\title{
The research on the asset quality, risk management capability and scale difference of commercial banks _-Based on panel data of 36 listed banks
}

\author{
Yingchan $\mathrm{Ye}^{1, *}$ HongMei Zhang ${ }^{2}$ \\ ${ }^{1}$ School of Big Data Application and Economics, Guizhou University of Finance and Economics \\ ${ }^{2}$ School of Big Data Application and Economics, Guizhou University of Finance and Economics \\ *Yingchan Ye.Email:1148895762@qq.com
}

\begin{abstract}
Under the COVID-19, non-performing loan ratio is increasing, and it has been harder to handle the non-performing asset. Therefore, it is more difficult for business banks to prevent from deterioration of asset quality in current days.Based on this, in order to prevent the risk of rapid deterioration of bank asset quality, this article analyzes the pressure of asset quality deterioration of my country's commercial banks at this stage based on the data of the first half of 2020, and is based on the panel data of 36 commercial banks listed on my country's A-shares from 2016 to 2020 , Using the system GMM model, analyze the relationship between the deterioration of the asset quality of commercial banks and their risk management capabilities. The study found that the risk management capabilities of commercial banks can effectively help commercial banks alleviate the deterioration of asset quality.
\end{abstract}

Keywords:asset quality,commercial banks,non-performing rate,panel data,risk prevention and control.

\section{商业银行资产质量、风险管理能力与规模差异研究 基于 36 家上市银行面板数据}

叶璎婵 $1, *$ 张红梅 ${ }^{2}$

\author{
1 贵州财经大学大数据应用与经济学院 1 \\ 2 贵州财经大学大数据应用与经济学院 2 \\ *叶顼婵.电子邮箱: 1148895762@.9q.com
}

\begin{abstract}
摘要
在新冠疫情背景下，商业银行不良贷款率上升、不良资产处置压力激增，当前商业银行资产质量恶化风险的 防控难度增加。本文结合 2020 年上半年度数据分析现阶段我国商业银行资产质量恶化压力，并基于我国 $\mathrm{A}$ 股 上市的 36 所商业银行 2016 至 2020 年的面板数据，运用系统 GMM 模型，分析商业银行风险管理能力以及银 行间存在的异质性对商业银行资产质量的影响，并探究商业银行的资产质量恶化程度与其风险管理能力之间 的关系。研究发现：商业银行风险管理能力能够有效帮助商业银行缓解资产质量恶化。
\end{abstract}

关键字: 资产质量, 商业银行, 不良贷款率, 面板数据, 风险防控.

1. 引言

2020 年新冠肺炎的冲击无疑暴露了各个国家、 企业、银行和个人潜在的各种困境和缺陷。银行业
作为连接国家、企业和个人的纽带在这场疫情阻击 战中起着至关重要的地位, 但银行业作为金融业的 三大支柱之一，存在着风险滞后的特征，在新冠疫 
情的后续影响下，银行业可能是最后一个受到冲击 的行业, 特别是在近年来, 商业银行逾期贷款和不 良贷款占比不断攀升的 “不良双升”格局下，随着 疫情造成的外部环境不确定性增加, 全球金融市场 波动加剧，国内宏观经济下行压力犹存，本次疫情 进一步加速了经济下滑的趋势。虽然现阶段我国商 业银行整体经营水平和资产质量依然保持相对平稳 状态, 但是银行业可能存在表面上风平浪静, 实际 上是暴风雨前的平静的危险状态下。

\section{2. 文献综述}

银行资产质量受到诸多因素的影响, 如何应对 商业银行资产质量恶化风险当前国内外学者主要从 资产质量恶化风险产生原因、风险防范、风险化解 三个方面进行研究。

一是资产质量恶化风险产生原因。Avramidis （2020）[1]利用希腊危机期间向希腊企业提供的银 行贷款数据, 发现银行并不是将每个公司视为独立 实体, 在受到信贷冲击的情况下有关联公司可以进 入其关联集团的内部资本市场的情况下, 其贷款违 约的可能性较小, 不容易形成不良贷款。夏佳佳、 王守龙 (2020) [2]选取 2008 至 2018 年的季度数据, 结合当前我国经济新常态的形势, 将国内生产总值、 广义货币供应量、产能利用率、信贷规模、杜杆率、 不良贷款率等影响因素纳入一个框架体系进行研究, 结果表明这几个变量均对对商业银行资产质量变化 存在影响。

二是资产质量恶化风险防范。Huafeng Chen (2018) [3]对银行贷款体系的发展和战略选择提出 建议, 在进化博亦理论的基础上, 加入风险补偿基 金，建立了验证机制下科技型中小企业与银行贷款 的演化博峦模型, 降低银行资产质量恶化的风险。 黄淡涛 (2019) ${ }^{[4]}$ 从商业银行资产质量管控方面面 临的诸如资产配置、信用风险及负债期限匹配的非 均衡性较高等问题出发, 针对性提出加强商业银行 资产质量管控的新措施。

三是资产质量恶化风险化解。目前国内外对商 业银行资产质量恶化风险化解方面的研究主要集中 在降低不良贷款的产生率进而提高银行资产质量方 面。Leo Onyiriuba（2017） ${ }^{[5]}$ 认为, 企业拖延还贷款 的时间是其本性所致, 这往往会破坏银行正常经营 秩序, 而银行部分员工违规发放贷款, 凸显了银行 存在的系统性风险, 且这些都将使不良贷款发生率 大大上升, 降低了商业银行资产质量。张伟芹 （2016）[6]结合农村商业银行的不良贷款率一直稳 居榜首, 从规范银行高管职业行为、建立信贷质量追
责制度等方面针对性的提出提高农村商业银行资产 质量的建议和措施。

综上所述, 越来越多的学者更加重视 “不良双 升” 格局的变化, 随着内外部环境的变动, 特别是 现如今新冠疫情冲击下, 关于防范资产质量恶化风 险的研究尤为重要。为此, 本文基于我国 $\mathrm{A}$ 股上市 的 36 所商业银行 2016 至 2020 年的面板数据, 分析 商业银行的资产质量恶化程度与其风险管理能力之 间的关系, 以期为我国商业银行有缓解资产质量恶 化提供理论支撑。

\section{3. 疫情冲击对商业银行资产质量的影响}

\section{1. 商业银行资产质量表现}

在疫情懪发后我国迅速出台《关于进一步强化 金融支持防控新型冠状病毒感染肺炎疫情的通知》 号召我国商业银行不仅要展期或宽延贷款的归还， 而且需要增加放贷的力度和范围。银保监会在疫情 后首场发布会的焦点之一, 也是商业银行资产质量 问题。据银 2020 年上半年度年报显示, 36 家 $\mathrm{A}$ 股 上市银行整体经营情况较为稳健, 营业收入同比增 长 $6.8 \%$, 但受内外部环境及监管趋严的影响, 归属 于母公司净利润同比下滑 $9.3 \%$, 银行间分化持续, 城商行、农商行净利润同比仍能保持较低正增长。 从整体来说 36 家 $\mathrm{A}$ 股上市银行资产质量维持稳定, 不良贷款率的增长速度并不明显, 但银行不良资产 认定标准趋严, 二季度上市银行不良率环比一季度 提升 4BP, 对资产恶化风险仍不能掉以轻心。当前 银行不良暴露本身有一定滞后性, 疫情对银行在零 售、制造业等领域资产质量的影响逐步显现, 疫情 期间商业银行又出台了很多延期还本付息的支持政 策, 提供了更长的缓冲期, 风险暴露的时点也会因 此延后, 商业银行不良贷款余额和不良贷款率有所 承压, 盈利状况不容乐观, 后期商业银行可能面临 较大的不良率上升、不良资产增加和处置压力。

\section{2. 商业银行拨备计提力度加大}

从拨备覆盖率来看, 2020 年上半年行业整体拨 备覆盖率水平同比有所提升，36 家 $\mathrm{A}$ 股上市银行拨 备覆盖率算术平均值为 $268 \%$, 资产质量压力最大的 农商行与城商行则呈现出拨备覆盖不足的情况, 如 农商行、城商行的拨备覆盖率仅分别为 $118.14 \%$ 和 $152.83 \%$, 意味着在区域性银行中, 资产质量问题仍 然显得最为迫切。但当前我国商业银行整体拨备资 源仍然保持充足, 银行业整体风险抵补能力保持稳 定。就全国商业银行业来说, 2019 年底已有将近 6 万多亿的人民币的坏账拨备, 预计商业银行通过释 
放拨备来加强不良资产的核销力度, 就可整体把握 由疫情产生的对商业银行资产质量恶化的影响。

仍要注意一方面银行不可能把所有的储备资本 都用于填补今年疫情造成的资产质量恶化，另一方 面疫情对银行资产质量的影响逐步显现，尽管央行 已经放宽了存款准备金率和坏账拨备率使得现阶段 疫情造成的不良资产影响处于可控范围, 随着银保 监会监管进一步引导商业银行挤清账面水分, 各银 行在下半年度普遍加大计提及核销力度, 需持续结 合下半年度的数据重点关注银行资产质量的变化。

\section{4. 实证分析}

\section{1. 变量选择}

被解释变量：贷款是我国商业银行资金利用的 主要方式，金融机构不良贷款率是评价金融机构信 贷资产安全状况的重要指标之一。本文参考了曾俭 华 (2016) [7]、马存草 (2020) ${ }^{[8]}$ 的研究方法, 选取 了不良贷款率作为衡量疫情冲击下商业银行资产质 量恶化程度的代理变量。

解释变量: 本文的解释变量为商业银行的风险 管理能力, 具体包括商业银行的贷款结构、贷款迁 徙和风险监管, 本文选取公司贷款在商业银行贷款 中所占份额作为代理变量, 并使用资产负债率、流 动性比例、单一最大客户贷款比率、正常类贷款迁 徙率、核心一级资本充足率作为替代变量。

控制变量: 本文从盈利能力、拨备情况角度出 发, 选取了净利息收益率、拨备覆盖率、贷款拨备 率, 以控制不同规模的商业银行的规模差异。此外 本文还控制了年度效应和规模效应, 以此控制上市 年限、银行规模不同等因素造成的差异。

\section{2. 样本选择}

本文利用我国 A 股上市的 36 所商业银行 2016 至 2020 年的面板数据, 36 所上市商业银行包括 6 家大 型国有控股商业银行、9 家全国股份制商业银行、13 家城市商业银行和 8 家农村商业银行。数据来源于 36 家商业银行 2016 年至 2020 年上半年度的年度报 告, 部分数据因未披露, 则通过公式进行计算所得, 统计口径一致, 所选指标数据可信度高。

\section{3. 模型假设}

为研究我国 36 家 $\mathrm{A}$ 股上市的商业银行资产质量 与其风险管理能力的关系, 本文模型假设参考了李
鸿翔（2020） ${ }^{[9]}$ 的方法，从已上市的商业银行层面 构建如下基准回归模型:

$$
\begin{aligned}
\text { Bank_AS }_{\mathrm{it}}= & \alpha_{0}+\beta \text { Bank_RMC } \mathrm{RM}_{\mathrm{it}}+\gamma \text { Controls }_{\mathrm{it}} \\
& +\delta_{\mathrm{t}}+\mu_{\mathrm{i}}+\varepsilon_{\mathrm{i}}
\end{aligned}
$$

其中, 下标的 $\mathrm{i}$ 表示第 $\mathrm{i}$ 个银行, $\mathrm{t}$ 表示第 $\mathrm{t}$ 年, Bank_AS 表示商业银行的资产质量, Bank_RMC 表 示商业银行风险管理能力, 本文的基准模型使用公 司贷款占银行总贷款的比例作为核心自变量, 另外 使用商业银行的拨备情况、贷款迁徙和风险监管的 相关主要指标数据作为代替变量以进行稳健性检验。 Controls 代表控制变量, 包括盈利能力、信贷能力、 资本状况角度下的商业银行监管指标, $\alpha_{0}$ 为截距项, $\delta_{\mathrm{t}}$ 为年度效应, $\mu_{\mathrm{i}}$ 为规模效应, $\varepsilon_{\mathrm{it}}$ 为残差项。

由于银行业作为金融业的三大支柱之一，存在 着风险滞后的特征, 且商业银行资产质量受到经济 周期的影响, 其变动存在某种惯性, 上一期商业银 行的资产质量会对当期产生影响, 使用静态面板模 型可能会产生偏差, 需要使用动态面板模型解决。 本文使用系统 GMM 模型检验商业银行资产质量与 其风险管理能力的关系, 进一步解决了方程 (1) 可 能存在的内生性问题。具体的回归方程如下:

Bank_AS $S_{i t}=\alpha_{0}+\beta_{1}$ Bank_AS $S_{i, t-1}+\beta_{2}$ Bank_RMC ${ }_{i t}$

$$
+\gamma \text { Controls }_{\mathrm{it}}+\delta_{\mathrm{t}}+\mu_{\mathrm{i}}+\varepsilon_{\mathrm{it}}
$$

其中，等式右边增加了商业银行不良贷款程度 的一阶滞后项（Bank $\mathrm{AS}_{\mathrm{i}, \mathrm{t}-\mathrm{1}}$ ) ，其他变量与方程（1） 一致。本文使用了系统 GMM 模型能够有有效控制 商业银行不良贷款程度的前期值与误差项之间可能 存在的内生关联。

\section{表 1：描述性统计}

\begin{tabular}{|c|c|c|c|c|}
\hline 变量名称 & 均值 & 标准差 & 最大值 & 最小值 \\
\hline $\begin{array}{c}\text { 商业银行资产质 } \\
\text { 量恶化程度 }\end{array}$ & 0.0148 & 0.0034 & 0.0247 & 0.0075 \\
\hline 公司贷款占比 & 0.5615 & 0.2045 & 0.8648 & 0.0094 \\
\hline $\begin{array}{c}\text { 资产负债率 } \\
\text { 流动性比例 }\end{array}$ & 0.9266 & 0.0104 & 0.9580 & 0.9031 \\
\hline $\begin{array}{c}\text { 单一最大客户 } \\
\text { 贷款比率 }\end{array}$ & 0.0450 & 0.1532 & 1.2169 & 0.1419 \\
\hline $\begin{array}{c}\text { 核心级资本 } \\
\text { 充足率 }\end{array}$ & 0.1005 & 0.0156 & 0.1416 & 0.0793 \\
\hline 正常贷款迁徙率 & 0.0273 & 0.0226 & 0.1939 & 0.0045 \\
\hline 净利息收益率 & 0.0229 & 0.0153 & 0.2210 & 0.0125 \\
\hline 拨备覆盖率 & 2.4402 & 0.9064 & 5.2408 & 1.3244 \\
\hline 贷款拨备率 & 0.0336 & 0.0069 & 0.0519 & 0.0222 \\
\hline
\end{tabular}




\section{表 2 基准模型}

\begin{tabular}{|c|c|c|c|c|c|c|}
\hline 模型 & (1) & (2) & (3) & $(4)$ & $(5)$ & (6) \\
\hline 被解释变量 & \multicolumn{6}{|c|}{ 商业银行资产质量恶化程度：不良贷款率 } \\
\hline \multirow{2}{*}{ 公司贷款占比 } & $-0.0019^{* *}$ & & & & & \\
\hline & $(-2.1073)$ & & & & & \\
\hline \multirow{2}{*}{ 资产负债率 } & & $-0.0227^{* *}$ & & & & \\
\hline & & $(-2.2843)$ & & & & \\
\hline \multirow{2}{*}{ 流动性比例 } & & & $-0.0015^{* *}$ & & & \\
\hline & & & $(-2.1620)$ & & & \\
\hline \multirow{2}{*}{$\begin{array}{c}\text { 单一最大客户 } \\
\text { 贷款比率 }\end{array}$} & & & & $-0.0042^{* *}$ & & \\
\hline & & & & $(-2.1322)$ & & \\
\hline \multirow{2}{*}{ 核心一级资本充足率 } & & & & & $-0.0211^{* * *}$ & \\
\hline & & & & & $(-3.1419)$ & \\
\hline \multirow{2}{*}{ 正常贷款迁徙率 } & & & & & & $0.0150^{* * *}$ \\
\hline & & & & & & $(3.2496)$ \\
\hline \multirow{2}{*}{ 净利息收益率 } & $0.0167^{* *}$ & $0.0179^{* * *}$ & $0.0155^{* *}$ & $0.0170^{* *}$ & $0.0172^{* * *}$ & $0.0156^{* *}$ \\
\hline & $(2.5236)$ & (2.7012) & (2.3328) & $(2.5784)$ & $(2.6332)$ & $(2.3933)$ \\
\hline \multirow{2}{*}{ 拨备覆盖率 } & $-0.0044^{* * *}$ & $-0.0042^{* * *}$ & $-0.0043^{* * *}$ & $-0.0043^{* * *}$ & $-0.0044^{* * *}$ & $-0.0042^{* * *}$ \\
\hline & $(-30.0748)$ & $(-29.5573)$ & $(-30.7973)$ & $(-30.2632)$ & $(-30.9361)$ & $(-28.7937)$ \\
\hline \multirow{2}{*}{ 贷款拨备率 } & $0.3306^{* * *}$ & $0.3125^{* * *}$ & $0.3299^{* * *}$ & $0.3161^{* * *}$ & $0.3384^{* * *}$ & $0.3138^{* * *}$ \\
\hline & $(17.3267)$ & $(16.6265)$ & $(17.3940)$ & $(16.9839)$ & $(17.7432)$ & $(17.1486)$ \\
\hline \multirow{2}{*}{ 常数项 } & $0.0152^{* * *}$ & $0.0352^{* * *}$ & $0.0148^{* * *}$ & $0.0144^{* * *}$ & $0.0159^{* * *}$ & $0.0136^{* * *}$ \\
\hline & $(20.8581)$ & $(3.8081)$ & $(24.9258)$ & $(27.2702)$ & $(20.8295)$ & $(25.7966)$ \\
\hline \multirow{2}{*}{$\begin{array}{l}\text { 年度固定效应 } \\
\text { 规模固定效应 }\end{array}$} & 控制 & 控制 & 控制 & 控制 & 控制 & 控制 \\
\hline & 控制 & 控制 & 控制 & 控制 & 控制 & 控制 \\
\hline 观测值 & 180 & 180 & 180 & 180 & 180 & 180 \\
\hline $\mathrm{R}^{2}$ & 0.8475 & 0.8482 & 0.8477 & 0.8476 & 0.8525 & 0.8520 \\
\hline 上市银行数量 & 36 & 36 & 36 & 36 & 36 & 36 \\
\hline
\end{tabular}

注 $* * *$, **和*分别表示在 $1 \%, 5 \%$ 和 $10 \%$ 水平上显著。

\section{4. 实证检验}

\subsection{1 基准模型}

本文首先使用了面板固定效应法对模型进行估 计, 其结果显示, 商业银行公司贷款占比的回归系 数为 -0.0019 , 在 $5 \%$ 的置信水平上显著, 商业银行公 司贷款占比的回归系数为负, 说明在其他条件不变 的情况下, 公司贷款占比越少的上市商业银行, 其 银行资产质量即不良贷款率越高。这一结果说明, 商业银行风险管理能力不足的上市商业银行, 商业 银行所面临的资产质量恶化的风险越大、影响越深, 商业银行的风险管理在上市银行中起到了风险调控 的作用, 对疫情等突发重大公共卫生安全事件等造 成的冲击起到了保护作用。由模型的（2）到（5） 可见，本文使用替代变量资产负债率、流动性比例、 单一最大客户贷款比率、核心一级资本充足率得到 为负的回归系数, 与模型 (1) 的结论一致, 模型 （6）使用的替代变量正常贷款迁徙率得到为正的回 归系数, 说明其他条件不变的情况下, 正常贷款迁
徙率越少的上市商业银行其不良贷款率越低, 资产 质量越好。

\subsection{2. 内生性检验}

为进一步减少可能存在的内生性问题，本文使 用系统 GMM 模型检验商业银行资产质量恶化与其 风险管理能力的关系。如表 3 所示，核心自变量的 回归系数与基准模型一致，商业银行不良贷款程度 滞后一期的回归系数均为正，说明目前我国商业银 行在疫情冲击下资产质量仍然保持稳定状态，商业 银行的风险管理能力在目前阶段能够有效维护商业 银行的资产质量在疫情冲击下不恶化。此外, 本文 对系统 GMM 模型进行了 AR (1)、AR (2) 检验 和 Sargan 检验, 检验结果表明误差项不存在二阶序 列自相关问题和度过识别问题，因此所得回归结果 是可靠、有效的。 


\section{表 3 系统 GMM 模型}

\begin{tabular}{|c|c|c|c|c|c|c|}
\hline 模型 & (1) & $(2)$ & (3) & (4) & $(5)$ & (6) \\
\hline 被解释变量 & \multicolumn{6}{|c|}{ 商业银行资产质量恶化程度: 不良贷款率 } \\
\hline \multirow{2}{*}{$\begin{array}{l}\text { 商业银行资产质量 } \\
\text { 恶化程度滞后一期 }\end{array}$} & $0.4807^{* * *}$ & $0.1742^{* * *}$ & $0.3684^{* * *}$ & $0.4257^{* * *}$ & $0.6838^{* * *}$ & $0.2556^{* * *}$ \\
\hline & $(9.1207)$ & $(3.5897)$ & $(7.1536)$ & $(6.8125)$ & $(9.2766)$ & $(4.2409)$ \\
\hline \multirow{2}{*}{ 公司贷款占比 } & $-0.0069^{* * *}$ & & & & & \\
\hline & $(-3.0049)$ & & & & & \\
\hline \multirow{2}{*}{ 资产负债率 } & & $-0.1304^{* * *}$ & & & & \\
\hline & & $(-4.0581)$ & & & & \\
\hline \multirow{2}{*}{ 流动性比例 } & & & $-0.0041^{* * *}$ & & & \\
\hline & & & $(-3.4567)$ & & & \\
\hline \multirow{2}{*}{$\begin{array}{c}\text { 单一最大客户 } \\
\text { 贷款比率 } \\
\end{array}$} & & & & $-0.0146^{* * *}$ & & \\
\hline & & & & $(-4.2895)$ & & \\
\hline \multirow{2}{*}{ 核心一级资本充足率 } & & & & & $-0.0834^{* * *}$ & \\
\hline & & & & & $(-2.8941)$ & \\
\hline \multirow{2}{*}{ 正常贷款迁徙率 } & & & & & & $0.0348^{* * *}$ \\
\hline & & & & & & $(4.8908)$ \\
\hline 控制变量 & 控制 & 控制 & 控制 & 控制 & 控制 & 控制 \\
\hline 年度固定效应 & 控制 & 控制 & 控制 & 控制 & 控制 & 控制 \\
\hline 规模固定效应 & 控制 & 控制 & 控制 & 控制 & 控制 & 控制 \\
\hline AR (2) 检验 & 0.9821 & 0.9444 & 0.8352 & 0.7653 & 0.9499 & 0.9444 \\
\hline \multirow{2}{*}{ Sargan 检验 } & 16.5736 & 5.8369 & 16.1433 & 19.5922 & 14.551 & 21.4078 \\
\hline & $(0.0843)$ & $(0.5589)$ & $(0.0956)$ & $(0.1334)$ & $(0.1493)$ & $(0.0842)$ \\
\hline 观测值 & 180 & 180 & 180 & 180 & 180 & 180 \\
\hline 上市银行数量 & 36 & 36 & 36 & 36 & 36 & 36 \\
\hline
\end{tabular}

注 $* * *, * *$ 和*分别表示在 $1 \%, 5 \%$ 和 $10 \%$ 水平上显著。

\subsection{3. 异质性检验}

为验证不同资产规模、经营形式、主营地域、 上市年限等可能存在的差异, 对本文样本中的 6 家 大型国有控股商业银行、9 家全国股份制商业银行、 13 家城市商业银行和 8 家农村商业银行进行异质性 分析。由表 4 可以看到, 当样本为大型国有控股商 业银行时, 核心自变量的回归系数与基准模型和系 统 GMM 模型保持一致，且在 $5 \%$ 水平上显著; 当样 本为农村商业银行时, 核心自变量的回归系数均为 正数, 且在 $1 \%$ 水平上显著; 而样本为股份制和城市 商业银行时, 核心自变量的回归系数基本不显著, 这表明商业银行风险管理能力能够有效帮助商业银 行缓解资产质量恶化的现象主要表现在大型国有控 股商业银行。这是因为国有行、农商行存款成本相 对刚性, 在宽信用的政策导向下, 国有行和农村行 享受的政策红利效应要大于股份行和城商行。从资 本充足率看, 城商行与农商行的资本补充压力较大, 且有加剧趋势, 而国有行的服务对象与实体经济之 间的关联性更高，从而产生了国有行的风险管控更 能帮助其缓解资产质量恶化风险的现象。

\section{5. 结论与建议}

本文使用 2016-2020 年 36 个我国上市商业银行 的面板数据, 以商业银行的不良贷款率作为衡量银 行资产质量恶化程度的代理变量, 实证分析了商业 银行的资产质量恶化程度与其风险管理能力之间的 关系。研究发现：商业银行风险管理能力能够有效 帮助商业银行缓解资产质量恶化。基于上述结论,本 文提出以下几点政策建议:

首先, 及时把控宏观经济走势, 维持商业银行 的风险管理能力, 不能因疫情冲击和外部环境的下 行压力导致商业银行的盈利能力大幅波动。监管部 门应该以市场为导向，在控制好风险的情况下，注 重商业银行的贷款结构的调整, 确保商业银行有能 力自行承担损失, 能够有效抑制风险资产的增长, 保护银行客户的权益。

其次, 坚决治理各种粉饰报表的行为。督促商 业银行对于不良贷款率、拨备覆盖率等指标的真实 披露，切实做好资产分类，足额计提拨备，保障商 业银行有足够的风险抵补水平能够应对资产质量恶 化。参照银行近 5 年来的不良率的变动, 各商业银 行也可以根据去年年底所作的坏账拨备覆盖率来针 


\section{表 4 异质性分析}

\begin{tabular}{|c|c|c|c|c|c|c|c|c|c|c|c|c|}
\hline 模型 & (1) & (2) & (3) & (1) & (2) & (3) & (1) & (2) & (3) & (1) & (2) & (3) \\
\hline 规模 & \multicolumn{3}{|c|}{ 大型国有控股商业银行 } & \multicolumn{3}{|c|}{ 全国股份制商业银行 } & \multicolumn{3}{|c|}{ 城市商业银行 } & \multicolumn{3}{|c|}{ 农村商业银行 } \\
\hline \multirow{2}{*}{$\begin{array}{c}\text { 公司贷款 } \\
\text { 占比 }\end{array}$} & $-0.0330^{* * * *}$ & & & 0.0011 & & & \begin{tabular}{|l|l|}
-0.0003 \\
\end{tabular} & & & $0.0089^{* * *}$ & & \\
\hline & $(-3.9121)$ & & & $(1.2981)$ & & & $(-1.1974)$ & & & (3.6598) & & \\
\hline \multirow{2}{*}{$\begin{array}{c}\text { 核心一级资本 } \\
\text { 充足率 }\end{array}$} & & $-0.1062^{* *}$ & & & 0.0245 & & & -0.0100 & & & $0.1390^{* * *}$ & \\
\hline & & $\begin{array}{c}(- \\
2.7174)\end{array}$ & & & $(1.0154)$ & & & $(-0.8367)$ & & & (3.6598) & \\
\hline \multirow{2}{*}{$\begin{array}{l}\text { 正常贷款 } \\
\text { 迁徙率 }\end{array}$} & & & $0.0547^{* *}$ & & & $0.0153^{* *}$ & & & 0.0120 & & & $0.0529^{* * *}$ \\
\hline & & & $(1.9021)$ & & & $(2.1927)$ & & & $(-1.5006)$ & & & $(4.7453)$ \\
\hline 控制变量 & 控制 & 控制 & 控制 & 控制 & 控制 & 控制 & 控制 & 控制 & 控制 & 控制 & 控制 & 控制 \\
\hline 年度固定效应 & 控制 & 控制 & 控制 & 控制 & 控制 & 控制 & 控制 & 控制 & 控制 & 控制 & 控制 & 控制 \\
\hline 规模固定效应 & 控制 & 控制 & 控制 & 控制 & 控制 & 控制 & 控制 & 控制 & 控制 & 控制 & 控制 & 控制 \\
\hline 观测值 & 30 & 30 & 30 & 45 & 45 & 45 & 65 & 65 & 65 & 40 & 40 & 40 \\
\hline $\mathrm{R}^{2}$ & 0.9826 & 0.8488 & 0.9065 & 0.8361 & 0.8570 & 0.8350 & 0.9775 & 0.9648 & 0.9650 & 0.8221 & 0.8107 & 0.8474 \\
\hline 上市银行数量 & 6 & 6 & 6 & 9 & 9 & 9 & 13 & 13 & 13 & 8 & 8 & 8 \\
\hline
\end{tabular}

注***，**和*分别表示在 $1 \%, 5 \%$ 和 $10 \%$ 水平上显著。

对性融资，采用不良资产核销、抵债资产处理等多 种方式加大不良资产处理。在疫情防控下，保持制 定合理的财务风险监督政策也是商业银行防范资产 质量恶化的有效对策。

最后, 加快推进银行数字化转型, 利用大数据 技术创新构建商业银行云平台。为了有效把控疫情 影响下不良贷款发生率, 商业银行可以利用大数据 技术构建专属的云平台, 利用借款主体在银行的财 务信息和信用信息，关注疫情后的不良贷款迁徙率， 建立全面的审核、监督机制, 做好对肩宽主体的信 息把握和定期监督, 也便于商业银行可以在贷款后 考察借款主体的财务运转状况, 更加全面地进行信 用管理，防治企业和个人发生失信行为。

\section{致谢}

本研究得到 2020 贵州财经大学在校学生科学研 究项目《数字经济下贵州省农业经营主体云融资模 式创新研究》（2020ZXSY03）及《普惠金融背景下 贵州省数字化乡村发展水平与影响因素研究》

（2020ZXSY16）的大力资助。

\section{参考文献}

[1] Avramidis Panagiotis, Asimakopoulos Ioannis, Malliaropulos Dimitris, Travlos Nickolaos G.. Do banks appraise internal capital markets during credit shocks? Evidence from the Greek crisis[J]. Journal of Financial Intermediation, 2020 (prepublish).
[2] 夏佳佳, 王守龙. 经济新常态下商业银行资产质量 影响因素研究[J]. 河南工程学院学报(社会科学 版), 2020, 35(01): 18-23+80.

[3] Huafeng Chen, Mu Zhang,Junmeng Lu. Simulation Study on Evolutionary Game Model between Technological Small and Medium Enterprises and Banks under Verification System[J]. Journal of Risk Analysis and Crisis Response, 2018, 8(2).

[4] 黄炏涛. 商业银行资产质量管控的新问题和新思 考[J]. 现代经济信息, 2019(24): 298.

[5] ONYIRIUBA L. Discretionary loan loss provisions and systemic rick in the banking industry[J]. Sccounting perspectives, 2017( 2):56 -57.

[6] 张伟芹. 提升农村商业银行信贷资产质量的思考 [J]. 北京财贸职业学院学报, 2016, 32(04): 21-25.

[7] 曾俭华.经济周期对银行资产质量影响的量化研 究[J].金融监管研究,2016(01):9-22.

[8] 马存草. 拨备监管标准调整对银行资产质量和信 贷投放影响的研究[D].山东大学, 2020 .

[9] 李鸿翔.互联网消费信贷、传统银行信贷与区域 差异——基于省级面板数据的检验 $[\mathrm{J}]$. 管理现代 化,2020,40(05):1-4. 